\title{
Sensor Properties and Surface Characterization of Silver-deposited SPR Optical Fibers
}

\author{
Masaru MitsuSHIo, ${ }^{* \dagger}$ Yasuyuki ABE, ${ }^{* *}$ and Morihide Higo* \\ *Department of Chemistry, Biotechnology, and Chemical Engineering, Graduate School of Science and \\ Engineering, Kagoshima University, 1-21-40 Korimoto, Kagoshima 890-0065, Japan \\ **Department of Applied Chemistry and Chemical Engineering, Graduate School of Science and Engineering, \\ Kagoshima University, 1-21-40 Korimoto, Kagoshima 890-0065, Japan
}

\begin{abstract}
The response curves and sensor properties of silver-deposited optical fibers with Ag film thicknesses of $20.0-80.0 \mathrm{~nm}$ based on surface plasmon resonance (SPR) were investigated. The response of the Ag-deposited optical fiber sensor depends on the thickness of the Ag film. The Ag-deposited optical fiber sensors show higher responses than those deposited with $\mathrm{Au}$. The reflection properties of Ag films with thicknesses of $30.5-70.2 \mathrm{~nm}$ due to the SPR phenomenon were also measured and considered. The surfaces of these $\mathrm{Ag}$ films consist of various spherical grains with diameters of $30-90 \mathrm{~nm}$ and the surface height distribution is almost random, having a value of more than $8 \mathrm{~nm}$. X-ray photoelectron spectroscopy (XPS) showed the presence of very thin $(0.3 \mathrm{~nm})$ native oxide layers on the Ag films. The Ag-deposited optical fiber sensor exhibited no change in the sensor properties following prolonged use for 4 months. The response curves of the Ag-deposited optical fiber sensors by use of SPR theoretical equations were calculated and compared with those obtained by experimentation.
\end{abstract}

(Received May 21, 2010; Accepted July 24, 2010; Published September 10, 2010)

\section{Introduction}

Traditional surface plasmon resonance (SPR) sensors measure an intensity of reflected light from a bulk prism with a thin metal film. ${ }^{1-3}$ The resonance angle at which the coupling of the incident light and the surface plasmon waves occurs is measured at the minimum reflection intensity. The attenuation properties of the SPR phenomenon depend on the dielectric constant $\left(\varepsilon_{\mathrm{r}}+\varepsilon_{\mathrm{i}} i\right)$ of the deposited metal, where $\varepsilon_{\mathrm{r}}$ and $\varepsilon_{\mathrm{i}}$ are the real and imaginary parts. The $\varepsilon_{\mathrm{r}}+\varepsilon_{\mathrm{i}} i$ account for the reflection and absorption of light in the metal, respectively. ${ }^{4-7}$ Narrow resonance is obtained in the SPR reflection spectra due to a small damping if $\left|\varepsilon_{\mathrm{r}}\right| \gg 1$ and $\left.\left|\varepsilon_{\mathrm{r}}\right| \gg\left|\varepsilon_{\mathrm{i}}\right|\right|^{4,6,7}$ Gold (Au) and silver (Ag) are the most widely used metals for SPR experiments. The sharpest peak is produced by Ag whose dielectric constant $(-18.22+0.48 i$ at $632.8 \mathrm{~nm})$ has the highest $\left|\varepsilon_{\mathrm{r}} / \varepsilon_{\mathrm{i}}\right|$ ratio (38.0). ${ }^{6,7}$ Gold $(\mathrm{Au})$ with a dielectric constant of $-10.92+1.49 i$ at $632.8 \mathrm{~nm}\left(\left|\varepsilon_{\mathrm{r}} / \varepsilon_{\mathrm{i}}\right|=7.33\right)^{7}$ produces a broader peak than $\mathrm{Ag}$, however, Au also gives good SPR spectra due to the inertness of Au. The SPR sensors allow quick determination of the refractive index (RI) of a sample with high accuracy. However, the usual SPR sensor systems utilize bulk optical configurations that are relatively large and expensive and also limited by the use of a coupling prism.

An optical fiber sensor system based on SPR allows the development of remote sensing, continuous analysis, and in situ

To whom correspondence should be addressed.

E-mail: m-mitsus@apc.kagoshima-u.ac.jp

Y. A. present address: Jasco International Co., Ltd., 2-4-21

Sennin, Hachioji, Tokyo 193-0835, Japan. monitoring with an inexpensive and disposable sensor device. ${ }^{1-3}$ Sensor systems which scan the wavelength ${ }^{8-17}$ or change the angle of incident light ${ }^{18-28}$ have been proposed. Though another type of sensor system based on SPR does not need a change in the incident angle, it needs many optical parts for its construction. $^{29-37}$ Theoretical analyses and modeling for the responses of the metal-deposited optical fiber sensors have been carried out. ${ }^{38-42}$ We previously developed a small and simple Au-deposited optical fiber sensor, where the core of the optical fiber is entirely covered with a Au film, and the transmitted light intensity through the sensor is measured without scanning the wavelength or changing the angle of incident light. ${ }^{43-48}$ The sensor properties were evaluated by use of various samples. ${ }^{43-48}$ We then simplified the structure of the sensor element of the $\mathrm{Au}$-deposited optical fiber sensor; the Au film was deposited on half of the core of the optical fiber. ${ }^{49}$ This simplified sensor element exhibits better properties than those of previous elements. ${ }^{49}$ Furthermore, we also fabricated metal-deposited optical fiber sensors with $\mathrm{Cu}$ and $\mathrm{Al}$ and reported the response curves and sensor properties for the first time..$^{50}$ Numerical calculations of the response curves for the sensors were also performed with SPR theoretical equations and the calculated curves were compared with the experimental results. ${ }^{49,50}$ These sensors promise the development of a new analytical technique for use in applications.

In the present paper, we report the responses and properties of the Ag-deposited optical fiber sensors with various Ag film thicknesses. The reflection properties of thin Ag films due to the SPR phenomenon were also observed with a commercial SPR sensor system. The surface morphology of the Ag films was observed by atomic force microscopy (AFM). ${ }^{51-54} \mathrm{X}$-ray photoelectron spectroscopy (XPS) ${ }^{55,56}$ of the surfaces of the Ag 
films deposited on glass substrates revealed the presence of very thin oxide layers on these $\mathrm{Ag}$ surfaces. The numerical calculations of the response curves for these sensors were performed and the theoretical curves were compared with the corresponding experimental results. The present work is a thorough study of the Ag-deposited SPR optical fiber sensors along with the surface characterization of the Ag films by AFM and XPS. We demonstrate the usefulness of the Ag-deposited optical fiber as a sensor for a refractometer.

\section{Experimental}

\section{Construction of the sensors}

The preparation of the sensor elements of the metal-deposited optical fiber sensors and the sensor system were reported in the previous paper. ${ }^{46-50}$ A part $(10 \mathrm{~cm}$ long) of the clad and the jacket of a step-index multi-mode optical fiber (Showa Electric Wire \& Cable, NJ-PF200/300) was removed by immersing the optical fiber in concentrated sulfuric acid. The Ag film was deposited on half of the core $(200 \mu \mathrm{m}$ in diameter) of the optical fiber by evaporation of $\mathrm{Ag}$ (Mitsuwa Chemicals, $>99.99 \%$ ) at a rate of $1.0 \mathrm{~nm} / \mathrm{s}$ in a high vacuum $\left(<6 \times 10^{-4} \mathrm{~Pa}\right)$ at room temperature. The deposited Ag film on the core has a thickness distribution in which the maximum value $(20.0-80.0 \mathrm{~nm})$ represents the thickness. ${ }^{49,50}$ The uncertainty of the Ag thickness was less than $0.2 \mathrm{~nm}$.

The sensor element and Teflon tubes for a sample inlet and an outlet were fixed in a glass tube $(12 \mathrm{~cm}$ long and $0.3 \mathrm{~cm}$ in diameter) with resin to form a sensor cell. Methanol solutions of benzyl alcohol or ethylene glycol maintained at $25^{\circ} \mathrm{C}$ were then allowed to flow through the sensor cell.

\section{Sensor system and apparatus}

An edge of the optical fiber of the sensor was illuminated with a He-Ne laser (Melles Griot, V05LHR151, $632.8 \mathrm{~nm}$ ). The light transmitted through the sensor was measured with an optical multimeter (ILX Lightwave, OMM-6810B) equipped with a $\mathrm{Si}$ detector (ILX Lightwave, VOMM-6722B). The light intensity was converted to digital data with a digital multimeter (Yokogawa, 755501-1) used as an A/D converter and then monitored with a computer (NEC, PC-9821 Xs). The refractivities of the samples were measured with an Abbe refractometer (Atago, DR-A1) and the uncertainties were less than 0.002 RI units.

\section{Measurements of SPR spectra}

The SPR spectra of the Ag films with thicknesses of $30.5-70.2 \mathrm{~nm}$ were measured at room temperature $\left(25-26^{\circ} \mathrm{C}\right)$ with an SPR sensor system (DKK SPR-20). The metal films were prepared on cover glass (Iwaki Clinical Test Ware 2918, $18 \times 18 \mathrm{~mm}^{2}$ ) by vacuum evaporation at room temperature. The reflection properties for air, methanol, and a methanol solution of benzyl alcohol were obtained with wedge-shaped light $(660 \mathrm{~nm})$ with a $10^{\circ}$ of the central angle and a data collection interval of about $0.04^{\circ} .50$

\section{Morphology observation with AFM}

The AFM images (256 pixels wide) of the Ag films deposited on cover glass were taken with a Digital Instruments NanoScope III operating in contact mode by use of $\mathrm{Si}_{3} \mathrm{~N}_{4}$ cantilevers of $200 \mu \mathrm{m}$ long and having a force constant of $0.06 \mathrm{~N} \mathrm{~m}^{-1}$. The images were automatically plane-fitted to account for sample tilt, and flattened by use of the standard NanoScope III software. ${ }^{51-54}$

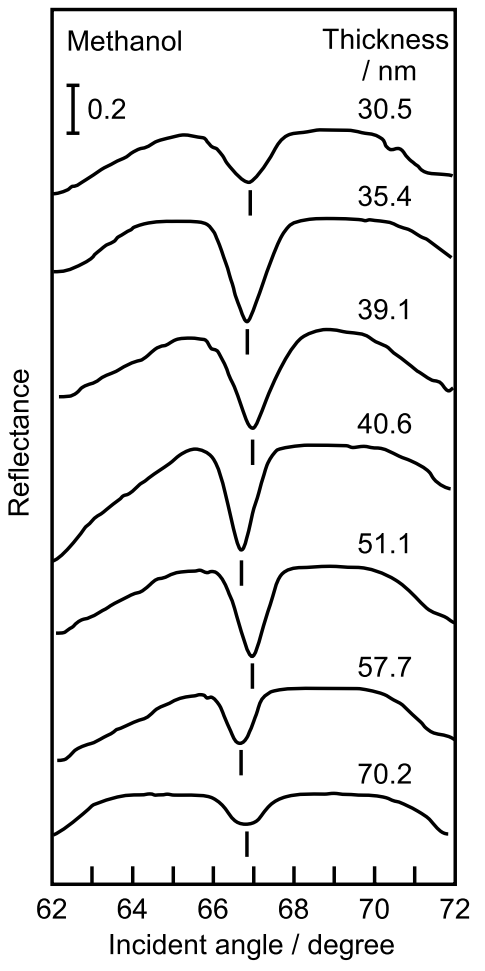

Fig. 1 SPR spectra of Ag films with various Ag thicknesses deposited on cover glass for methanol with a refractivity of $1.327 \mathrm{RI}$ units.

\section{Surface characterization with XPS}

The XPS spectra of the Ag films deposited on glass substrates were measured with a Shimadzu ESCA-1000 using $\mathrm{Mg} K_{\alpha}$ radiation $(1253.6 \mathrm{eV})$. The photoelectrons emitted normal to the surface $\left(3 \times 10 \mathrm{~mm}^{2}\right)$ were analyzed with a data collection interval of $0.1 \mathrm{eV}$ and with an analyzer pass energy set at $15.75 \mathrm{eV}$. The resolution was estimated to be $1.1 \mathrm{eV}$ from the peak width of the $\mathrm{Ag} 3 \mathrm{~d}_{5 / 2}$ line at $368.3 \mathrm{eV}^{55}$ The binding energy was calibrated with respect to the $\mathrm{C} 1 \mathrm{~s}$ line of the surface at $285.0 \mathrm{eV} .55$

\section{Results and Discussion}

\section{Reflection properties of Ag films}

The reflection properties of $\mathrm{Ag}$ films with thicknesses of $30.5-70.2 \mathrm{~nm}$ deposited on cover glass were measured by SPR for air, methanol, and a 20 volume\% methanol solution of benzyl alcohol with refractivities of 1.000, 1.327, and $1.373 \mathrm{RI}$ units, respectively. Figure 1 shows the SPR spectra of these Ag films for methanol (1.327 RI units). The SPR angles and the full widths at half maximum (FWHM) of the peaks in these spectra for the refractivities of 1.000, 1.327, and 1.373 RI units are shown in Table 1. These values are averages of those obtained from three to eight spectra measured for Ag films of different thicknesses. Uncertainties in the degree values $\left(<0.2^{\circ}\right)$ are mainly due to standard deviations.

The peak intensity in the SPR spectrum of the thinnest $(30.5 \mathrm{~nm}) \mathrm{Ag}$ film was weak. The peak intensity was observed to increase as the film thickness increases and it is almost constant in the spectra of the Ag films with thicknesses of $35.4-51.1 \mathrm{~nm}$. On the other hand, the peak intensity was observed to weaken in the spectra of the films with thicknesses 
Table 1 SPR angles and full widths at half maximum (FWHM) (degree) of the peaks in the SPR spectra at different refractivities $(R)$ for the $\mathrm{Ag}$ films

\begin{tabular}{cccc}
\hline \multirow{2}{*}{ Thickness/nm } & \multicolumn{3}{c}{$R /$ RI unit } \\
\cline { 2 - 4 } & 1.000 & 1.327 & 1.373 \\
\hline 30.5 & $43.3(0.45)$ & $66.9(1.19)$ & $72.0(1.42)$ \\
35.4 & $43.2(0.37)$ & $66.8(0.89)$ & $71.9(1.11)$ \\
39.1 & $43.2(0.44)$ & $67.0(0.99)$ & $72.1(1.24)$ \\
40.6 & $43.2(0.49)$ & $66.6(0.79)$ & $71.9(1.03)$ \\
51.1 & $43.0(0.36)$ & $67.0(0.79)$ & $72.3(1.09)$ \\
57.7 & $43.1(0.43)$ & $66.6(0.67)$ & $72.0(0.81)$ \\
70.2 & $43.1(0.50)$ & $66.8(0.95)$ & $72.0(1.22)$ \\
\hline
\end{tabular}

Uncertainties are less than 0.2 degree.

of more than $51.1 \mathrm{~nm}$. Though the peak intensity depends on the film thickness, the peak position is almost constant within the uncertainty $\left(66.8 \pm 0.2^{\circ}\right)$. This intensity dependence on the $\mathrm{Ag}$ film thickness was observed for the other refractivities of 1.000 and 1.373 RI units.

The peaks in the spectra of the Ag films are sharper than those in the spectra of the Au films due to the larger value of the $\left|\varepsilon_{\mathrm{r}} / \varepsilon_{\mathrm{i}}\right|$ ratio (38.0) ${ }^{6,7,50}$ Since these evaporated $\mathrm{Ag}$ films have very thin $(0.3 \mathrm{~nm})$ native oxide layers on their surfaces, the oxide may contribute to the peaks as discussed below. The peak width becomes broader for the higher refractivities. Though the peak width depends on the refractivity of a sample, the half $\left(0.5^{\circ}\right)$ of the FWHM at the refractivities of 1.327 and 1.373 was used for the numerical calculations of the response curves of the Ag-deposited optical fiber sensors for simplicity as discussed below.

\section{Surface characterization of Ag films}

The surface morphology of the deposited $\mathrm{Ag}$ films was observed and characterized by both roughness analysis and bearing analysis of the AFM results. The roughness analysis gives the surface roughness (root-mean-square: $R_{\mathrm{ms}}$ ) over the sample surface, where $R_{\mathrm{ms}}$ corresponds to the standard deviation of the surface height $\left(z_{\mathrm{ij}}\right)$. The bearing analysis provides a method of plotting and analyzing the histogram of $z_{\mathrm{ij}}$ taken over the sample surface. Since the bearing analysis is very sensitive to the curvature of the image plane, a third-order polynomial plane fit was used to account for the sample tilt and the slight curvature. The peak in the histogram represents the distribution of $z_{\mathrm{ij}}$ and its width (full width at half-maximum: $W$ ) is a good measure of the surface roughness. If $z_{\mathrm{ij}}$ distributes randomly around the surface height at $0 \mathrm{~nm}$, the peak has a Gaussian shape with the standard deviation $R_{\mathrm{ms}}$. Thus, $W$ is represented by $2.36 R_{\mathrm{ms}}$ and most $(>95 \%)$ areas of the peak are in the $2 \mathrm{~W}$ region between $\pm W .^{51-54}$

Typical AFM images and bearing histograms of the Ag films with thicknesses of 29.9, 45.5, and $70.5 \mathrm{~nm}$ are shown in Fig. 2. The image size is $1 \times 1 \mu \mathrm{m}$ wide with a $20-\mathrm{nm}$ gray scale. The average values and standard deviations of $W, R_{\mathrm{ms}}$, and $W / R_{\mathrm{ms}}$ of four to six AFM images for different $\mathrm{Ag}$ films with each thickness are shown in Table 2. The surfaces of the Ag films consist of various spherical grains with diameters of $30-90 \mathrm{~nm}$, having an average grain size of about $60 \mathrm{~nm}$. The grains in this AFM image are separated by voids with a depth of up to about $4 \mathrm{~nm}$. The surface height $\left(z_{\mathrm{ijj}}\right)$ distributions are more than $8 \mathrm{~nm}$ and the widths $(W)$ are $2.61-3.84 \mathrm{~nm}$. The values $(2.02$ and 2.37) of $W / R_{\mathrm{ms}}$ are very close to 2.36 and suggest that the shape of the distributions is close to Gaussian and the surface heights
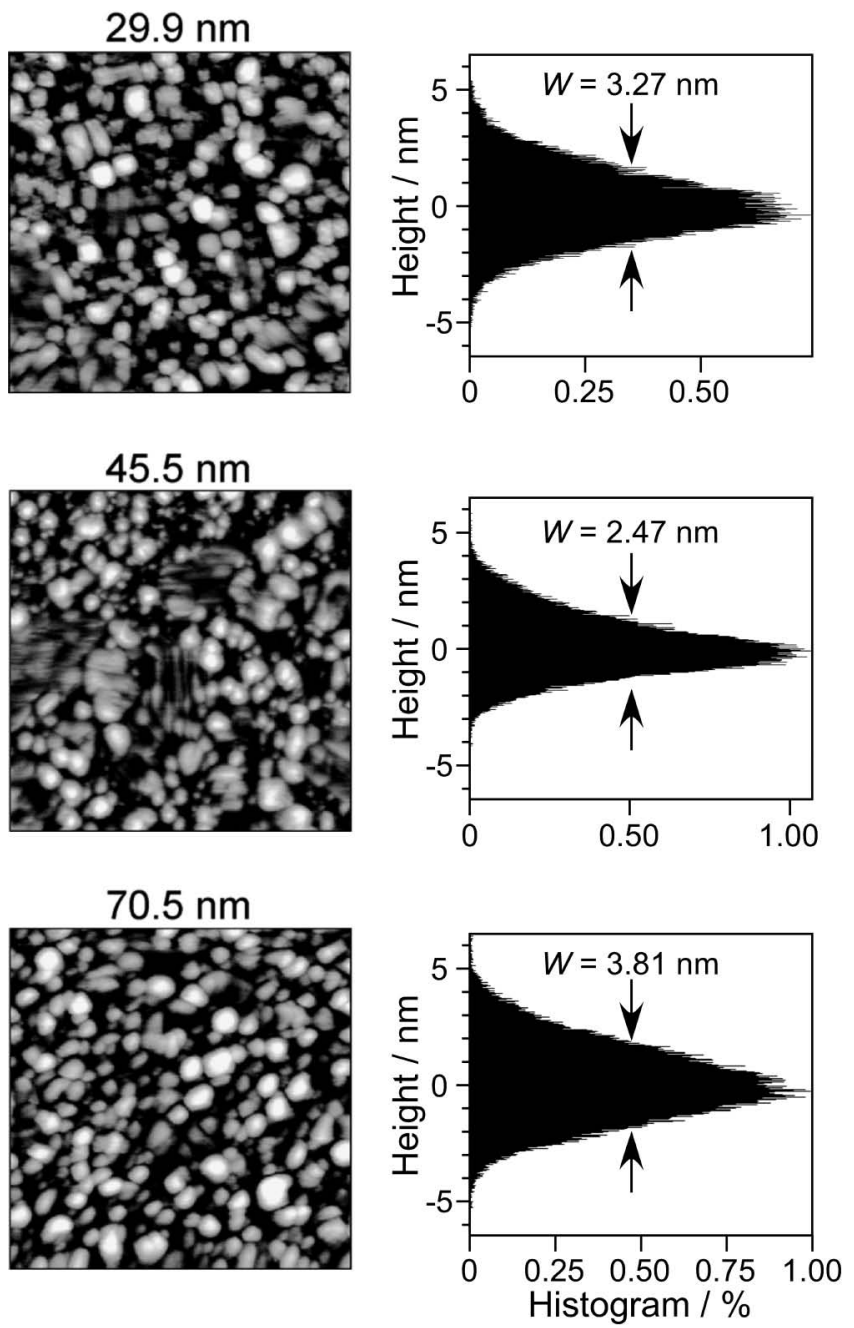

Fig. 2 AFM top views (left) and bearing histograms (right) of the $\mathrm{Ag}$ films with Ag thicknesses of 29.9, 45.5, and $70.5 \mathrm{~nm}$ deposited on cover glass at room temperature. Image size: $1 \times 1 \mu \mathrm{m}$ wide and a 20-nm gray scale.

Table 2 Bearing widths $(W)$, roughnesses $\left(R_{\mathrm{ms}}\right)$, and the ratios $\left(W / R_{\mathrm{ms}}\right)$ of the AFM images $(1 \times 1 \mu \mathrm{m}$ wide $)$ of the Ag films with thicknesses of 29.9, 45.5, and $70.5 \mathrm{~nm}$ deposited on cover glass at room temperature

\begin{tabular}{cccc}
\hline Thickness/nm & $W / \mathrm{nm}$ & $R_{\mathrm{ms}} / \mathrm{nm}$ & $W / R_{\mathrm{ms}}$ \\
\hline 29.9 & $3.12 \pm 0.23$ & $1.64 \pm 0.20$ & $2.02 \pm 0.32$ \\
45.5 & $2.61 \pm 0.33$ & $1.30 \pm 0.22$ & $2.02 \pm 0.15$ \\
70.5 & $3.84 \pm 0.45$ & $1.83 \pm 0.47$ & $2.37 \pm 0.12$ \\
\hline
\end{tabular}

Uncertainties are standard deviations.

$\left(z_{\mathrm{ij}}\right)$ are distributed almost randomly in these $\mathrm{Ag}$ films. The $\mathrm{Ag}$ films have the typical surface features in the first zone of structure zone models and the surface morphology is caused by the self-shadowing effect during the deposition at room temperature..$^{51-54}$

Silver films deposited on glass were characterized by XPS in order to obtain information on the surface state and the oxide layer. The peaks of $\mathrm{O} 1 \mathrm{~s}$ were observed in the XPS spectra of the Ag films. However, the peak intensity of $\mathrm{O} 1 \mathrm{~s}$ on the $\mathrm{Ag}$ films decreased after electron impact $(200 \mathrm{eV})$ on the surfaces at high vacuum, suggesting the presence of adsorbed species 


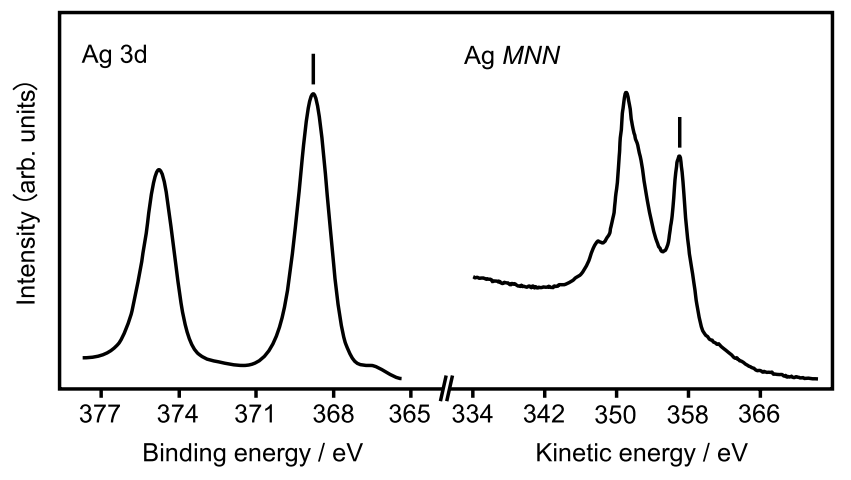

Fig. 3 XPS spectrum of $\mathrm{Ag} 3 \mathrm{~d}$ and Auger spectrum of $\mathrm{Ag} \mathrm{MNN}$ of a Ag film deposited on glass.

having oxygen atoms. Figure 3 shows the spectra of photoelectrons and Auger electrons obtained from the surfaces of a $\mathrm{Ag}$ film. The binding energy $(\mathrm{BE}=368.8 \mathrm{eV})$ of the photoelectrons of $\mathrm{Ag} 3 \mathrm{~d}_{5 / 2}$ and the kinetic energy $(\mathrm{KE}=357.0 \mathrm{eV})$ of the Auger electrons of Ag MNN give the modified Auger parameter $\left(\alpha^{\prime}=\mathrm{BE}+\mathrm{KE}=725.8 \mathrm{eV}\right)$. The corresponding values $\left(\mathrm{BE}=368.7, \mathrm{KE}=357.2\right.$, and $\left.\alpha^{\prime}=725.9 \mathrm{eV}\right)$ for the bulk of these $\mathrm{Ag}$ films measured after $\mathrm{Ar}^{+}$sputtering with a rate of about $0.1 \mathrm{~nm} / \mathrm{s}$ over the surface areas $\left(10 \times 10 \mathrm{~mm}^{2}\right)$ at high vacuum agreed well with these surface values. This agreement shows on the Ag surfaces the presence of very thin oxide layers of less than the escape depths $\left(\lambda_{\mathrm{e}}\right)$ of the photoelectrons $(1.6 \mathrm{~nm})$ and the Auger electrons $(1.0 \mathrm{~nm})$, which were calculated from the following equation,

$$
\lambda_{\mathrm{e}}=0.054 E^{1 / 2},
$$

where, $E$ is the $\mathrm{KE}(\mathrm{eV})$ of the electrons above $150 \mathrm{eV}^{56}$ The thickness of the oxide layer on the Ag films was estimated to be $0.3 \mathrm{~nm}$, as determined from the disappearance of the $\mathrm{O} 1 \mathrm{~s}$ peak by the $\mathrm{Ar}^{+}$sputtering.

\section{Sensor properties of Ag films}

The responses of a Ag-deposited optical fiber sensor with a film thickness of $45.2 \mathrm{~nm}$ to methanol solutions of benzyl alcohol with various concentrations are shown in Fig. 4. The concentration of the solution is a volume $\%(\%, \mathrm{v} / \mathrm{v})$. The refractivities and changes of the sample solutions are also shown in the figure. The Abbe refractometer showed small changes in the refractivities of the concentrations of 0.03 and $0.40 \%$. However, since the refractivities of the solutions were proportional to the concentrations in the range from 0 to $10 \%$ with a correlation coefficient of 0.997 , the values of the refractivities of 0.03 and $0.40 \%$ were calculated from those of the refractivities of 10.0 and $4.00 \%$, respectively.

When sample solutions of more than or equal to $0.03 \%$ were introduced into the sensor cell, the transmitted light intensity through the core of the Ag-deposited optical fiber decreased after $0.25 \mathrm{~min}$ from the sample introduction and became a constant value within $0.5 \mathrm{~min}$. The delay of $0.25 \mathrm{~min}$ is caused by the sample flow through the inlet of the sensor cell. The response time $(0.5 \mathrm{~min})$ is the time required for a complete exchange of a sample solution in the sensor cell. The detection limit of $0.03 \%$ and the change of $8.1 \times 10^{-5} \mathrm{RI}$ units with a signal to noise ratio $(S / N)$ of 6.1 were obtained by computer analysis. The signal was defined as a difference between the average of transmitted light intensities for $0.5 \mathrm{~min}$ of methanol

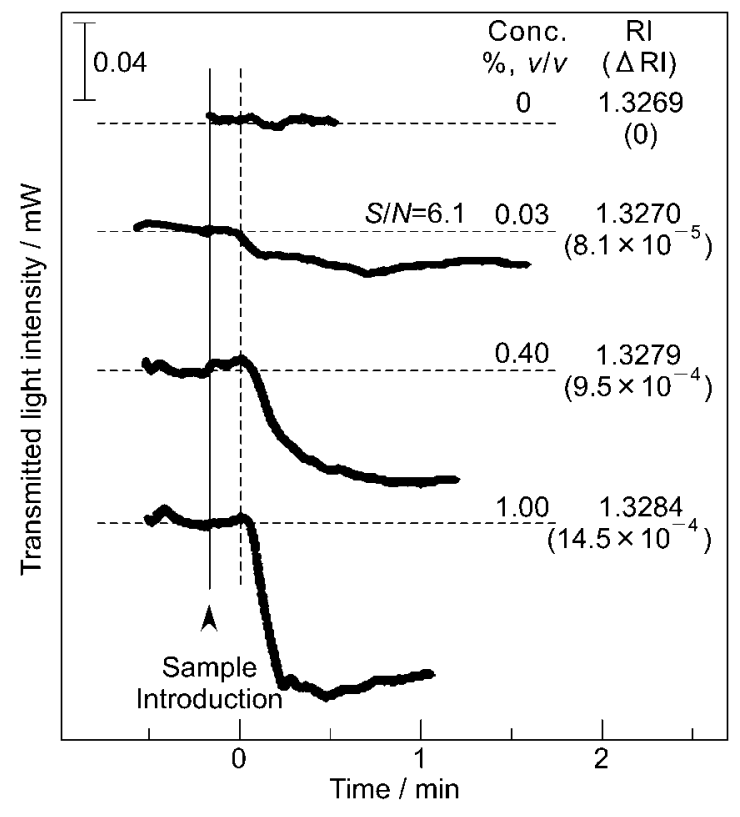

Fig. 4 Responses of the Ag-deposited SPR optical fiber sensor with a Ag film thickness of $45.2 \mathrm{~nm}$ to methanol solutions of benzyl alcohol with various concentrations. The concentration is a volume $\%(\%, \mathrm{v} / \mathrm{v})$. The refractive index $(\mathrm{RI})$ and the change $(\Delta \mathrm{RI})$ of the solution are also shown.

before the sample introduction and that of transmitted light intensities for $0.5 \mathrm{~min}$ after the light intensity became constant. The noise was twice that of the standard deviation of the transmitted light intensities for 0.5 min of the sample solution after the response. Our Au-deposited optical fiber sensor system had a detection limit of $0.02 \%$ and a change of $5.6 \times 10^{-5} \mathrm{RI}$ units for benzyl alcohol. ${ }^{49}$ Though the detection limit of the Ag-deposited optical fiber sensor is lower than that of our Au-deposited optical fiber sensor due to the lower sensitivity of the $\mathrm{Ag}$ films in the refractivity range of $1.327-1.355 \mathrm{RI}$ units as discussed below, the value $\left(8.1 \times 10^{-5} \mathrm{RI}\right)$ is almost equal to that of the Abbe refractometer used.

Figure 5 shows the response curves of Ag-deposited optical fiber sensors with thicknesses of $20.0-80.0 \mathrm{~nm}$ for the refractivity range from 1.327 to $1.430 \mathrm{RI}$ units. The response curve of the glass core without a $\mathrm{Ag}$ film $(0 \mathrm{~nm})$ is also shown for comparison. The transmitted light intensities for the solutions were measured and normalized by those for the solvent at 1.327 RI units. The refractivities at the minima in the response curves of these sensors are shown in Table 3. The values of the refractivities at the minima are averages of those from four to five response curves for different measurements of the sensors and the uncertainties are standard deviations $(<0.003 \mathrm{RI}$ units). The response of the sensor depends on the thickness of the $\mathrm{Ag}$ film; the minimum in the response curve shifts to a lower refractivity as the thickness increases. These Ag films have very thin native oxide layers with a thickness of $0.3 \mathrm{~nm}$. The oxide layers seem to be stable, because these sensors with a Ag film exhibited no change in the responses and properties when exposed to methanol solutions for periods of over 4 months.

The sensor properties are summarized in Table 4. The response is the minimum intensity in the response curve and is largest for the sensors with thicknesses of 20.0 and $30.3 \mathrm{~nm}$. The slope (sensitivity) and range are the values for the calibration curve for a methanol solution of ethylene glycol up to the 


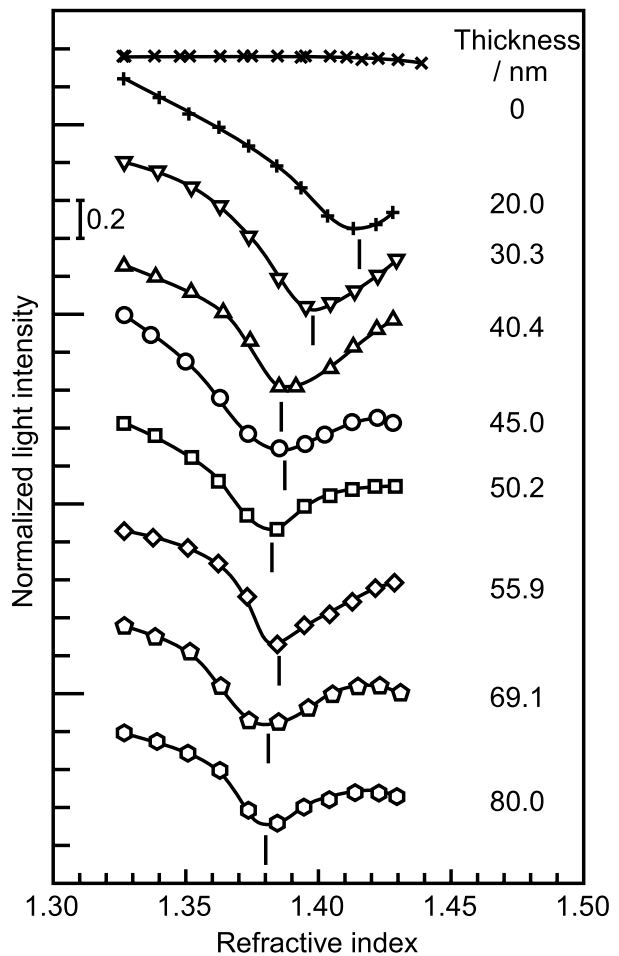

Fig. 5 Response curves of the Ag-deposited SPR optical fiber sensors with various Ag film thicknesses. The response curve of the bare core optical fiber without a $\mathrm{Ag}$ film $(0 \mathrm{~nm})$ is also shown.

Table 3 Refractivities (RI units) at the minima in the response curves of the Ag-deposited SPR optical fiber sensors with various film thicknesses

\begin{tabular}{ccc}
\hline Thickness/nm & Experimental & Theoretical \\
\hline 20.0 & 1.415 & \\
30.3 & 1.398 & 1.421 \\
40.4 & 1.387 & 1.399 \\
45.0 & 1.388 & 1.394 \\
50.2 & 1.383 & 1.391 \\
55.9 & 1.385 & 1.389 \\
69.1 & 1.381 & 1.386 \\
80.0 & 1.380 & 1.385 \\
\hline
\end{tabular}

The theoretical response curves were calculated for the sensors having no surface oxide layers. Uncertainties for the experimental and theoretical values are less than 0.003 and 0.001 RI units, respectively.

Table 4 Properties of the Ag-deposited SPR optical fiber sensors with various film thicknesses

\begin{tabular}{ccccc}
\hline & & \multicolumn{3}{c}{ Calibration curve } \\
\cline { 3 - 5 } $\begin{array}{c}\text { Thickness/ } \\
\text { nm }\end{array}$ & Response & Slope & $\begin{array}{c}\text { Range/ } \\
\text { RI unit }\end{array}$ & $\begin{array}{c}\text { Correlation } \\
\text { coefficient }\end{array}$ \\
\hline 20.0 & $0.27 \pm 0.06$ & $-4.9 \pm 1.5$ & $1.327-1.360$ & 0.994 \\
30.3 & $0.28 \pm 0.09$ & $-6.1 \pm 1.7$ & $1.327-1.359$ & 0.992 \\
40.4 & $0.34 \pm 0.07$ & $-8.0 \pm 2.2$ & $1.327-1.361$ & 0.997 \\
45.0 & $0.32 \pm 0.11$ & $-8.7 \pm 2.5$ & $1.327-1.355$ & 0.991 \\
50.2 & $0.48 \pm 0.11$ & $-5.7 \pm 1.4$ & $1.327-1.353$ & 0.992 \\
55.9 & $0.35 \pm 0.09$ & $-4.3 \pm 1.2$ & $1.327-1.351$ & 0.996 \\
69.1 & $0.47 \pm 0.07$ & $-5.9 \pm 1.7$ & $1.327-1.352$ & 0.992 \\
80.0 & $0.51 \pm 0.05$ & $-4.9 \pm 0.7$ & $1.327-1.351$ & 0.994 \\
\hline
\end{tabular}

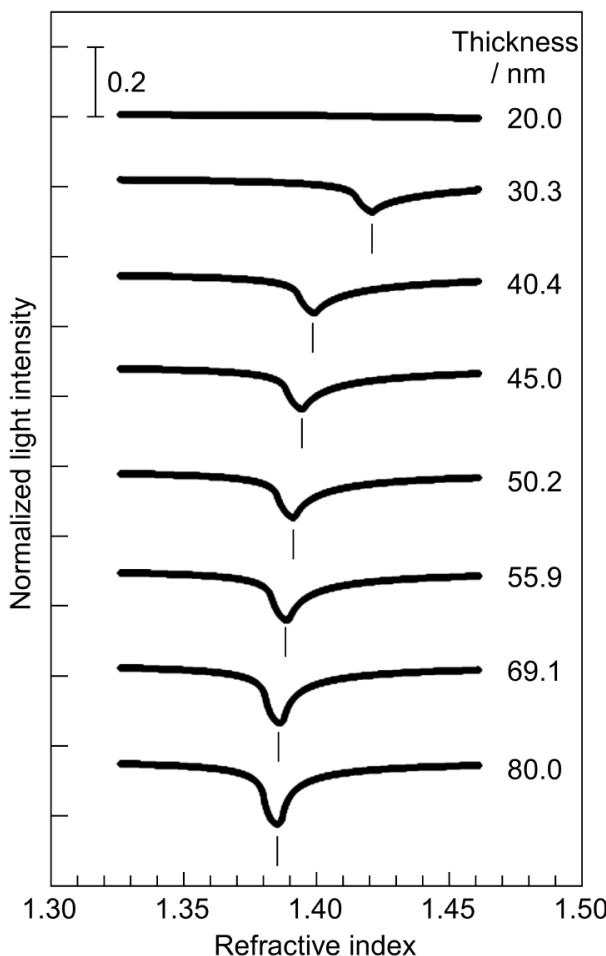

Fig. 6 Response curves of Ag-deposited SPR optical fiber sensors with various thicknesses of $\mathrm{Ag}$ films having no surface oxide layers calculated from SPR theoretical equations with consideration of $\mathrm{Ag}$ thickness distribution.

refractivity with the correlation coefficient shown in Table 4. The sensitivity is largest for the sensor with a thickness of $45.0 \mathrm{~nm}$ and the range is widest for the sensors with thicknesses of 20.0, 30.3, and $40.4 \mathrm{~nm}$. The sensors with $\mathrm{Ag}$ $\left(\left|\varepsilon_{\mathrm{r}} / \varepsilon_{\mathrm{i}}\right|=38.0\right)^{6,7,50}$ show higher responses than those with $\mathrm{Au}$ $\left(\left|\varepsilon_{\mathrm{r}} / \varepsilon_{\mathrm{i}}\right|=7.33\right) .^{7,50}$ Though these sensors with Ag films have similar response ranges from 1.327 to $1.351-1.361$ RI units, they have lower sensitivities than those $(-16.1 \pm 0.4)$ with $\mathrm{Au}$ films. ${ }^{50}$ The sensitivities of these sensors become higher at larger refractivities ( $>1.360 \mathrm{RI}$ units) near the minima of their responses. These results show that desirable properties of the Ag-deposited optical fiber sensor can be obtained by the selection of the film thickness.

Theoretical analysis of the response curves

The principal and models for the response of metal-deposited optical fiber sensors by SPR are based on the Kretschmann configuration..$^{38-42} \mathrm{Xu}$ et al. ${ }^{38,40}$ assumed that the models of SPR for bulk optics are satisfied by meridional rays in optical fibers. They calculated the optical power transmittance of a Au-deposited multi-mode optical fiber sensor as a function of wavelength. We have also considered the meridional rays and assumed single reflection without a range of incident angles in the metal-deposited multi-mode optical fibers with $\mathrm{Au}, \mathrm{Ag}, \mathrm{Cu}$, and $\mathrm{Al}$ for simplicity. ${ }^{47,49,50}$ We calculated the response curves of the sensors with these metal films having a thickness distribution without surface oxide layers. ${ }^{47,49,50}$ The theoretical response curves of the Ag-deposited optical fiber sensors were calculated from the following Eqs. (2) - (5), and the results are shown in Fig. 6.

The propagation constant of the evanescence wave $\left(k_{\mathrm{ev}}\right)$ is expressed as: 


$$
k_{\mathrm{ev}}=\frac{2 \pi}{\lambda} n_{\mathrm{c}} \sin \theta
$$

where $\lambda(632.8 \mathrm{~nm})$ is the wavelength of light, $n_{\mathrm{c}}(1.462 \pm$ $0.001 \mathrm{RI}$ units) the refractivity of the core, ${ }^{47-50}$ and $\theta$ the incident angle. The propagation constants of the surface plasmon waves are expressed as the following equations:

$$
\begin{aligned}
& k_{0}=\frac{2 \pi}{\lambda}\left(\frac{\varepsilon_{\mathrm{s}} \varepsilon_{\mathrm{m}}}{\varepsilon_{\mathrm{s}}+\varepsilon_{\mathrm{m}}}\right)^{1 / 2}, \\
& k_{\mathrm{r}}=k_{0}\left(\frac{2}{\varepsilon_{\mathrm{s}}+\varepsilon_{\mathrm{m}}}\right)\left(\frac{\varepsilon_{\mathrm{s}} \varepsilon_{\mathrm{m}}}{\varepsilon_{\mathrm{s}}+\varepsilon_{\mathrm{m}}}\right)^{3 / 2} \exp \left\{i \frac{4 \pi d_{\mathrm{m}}}{\lambda} \frac{\varepsilon_{\mathrm{m}}}{\sqrt{\varepsilon_{\mathrm{s}}+\varepsilon_{\mathrm{m}}}}\right\},
\end{aligned}
$$

where $k_{0}$ is the dispersion relation of SPR of a metal-vacuum interface in a one-sharp boundary model, $k_{\mathrm{r}}$ the perturbation to $k_{0}$ due to the finite physical volume of the metal, $\varepsilon_{\mathrm{s}}$ the dielectric constant of a sample approximated by $\varepsilon_{\mathrm{s}}=n_{\mathrm{s}}{ }^{2}\left(n_{\mathrm{s}}\right.$ is the refractivity of a sample), $\varepsilon_{\mathrm{m}}(-18.22)$ the real part of the dielectric constants of $\mathrm{Ag}$ at $632.8 \mathrm{~nm},{ }^{6,7}$ and $d_{\mathrm{m}}$ the film thicknesses of Ag.

When Eqs. (2) - (4) satisfy Eq. (5), the SPR phenomenon occurs and a part of incident light is absorbed:

$$
k_{\mathrm{ev}}=k_{0}+k_{\mathrm{r}}
$$

The intensity distribution for an incident angle of the collimated laser light was calculated as the following equation: $:^{38,47}$

$$
I(\theta)=\frac{n_{\mathrm{c}}^{2} \sin \theta \cos \theta}{\left(1-n_{\mathrm{c}}^{2} \cos ^{2} \theta\right)^{2}} .
$$

The reflectivity at the interface between the core and the sample was assumed to be unity below $1.462 \mathrm{RI}$ units where the total reflection occurs. The calculation was carried out for the refractivities from 1.327 to $1.462 \mathrm{RI}$ units with the assumption that the reflectivity in the angle range $(\theta \pm \Delta \theta)$ of SPR becomes zero. The half $\left(0.5^{\circ}\right)$ of the FWHM in the SPR spectrum of the $\mathrm{Ag}$ films for the refractivities of 1.327 and $1.373 \mathrm{RI}$ units was used for the value of $\Delta \theta$. The deposited Ag film layer on the half of the core has the geometric thickness distribution as shown in our previous paper, ${ }^{49}$ and thicknesses in the range from $10 \mathrm{~nm}$ to the maximum value were used for the calculation, because thicknesses below $10 \mathrm{~nm}$ did not satisfy the SPR conditions for the calculation. All the films with these thicknesses were also assumed to have an equal efficiency for SPR. ${ }^{49,50}$ The theoretical response curves were finally normalized by the intensities at $1.327 \mathrm{RI}$ units for the solvent.

Figure 6 shows the theoretical curves of the sensors with $\mathrm{Ag}$ film thicknesses of $20.0-80.0 \mathrm{~nm}$ and having no native oxide layers. The general agreement between the theoretical calculations and the experimental results were obtained for the sensors with thicknesses of $30.3-80.0 \mathrm{~nm}$. However, the theoretical curve of the sensor with a thickness of $20.0 \mathrm{~nm}$ has no minimum in the response range and is completely different from the experimental curve. The theoretical curves of the sensors with thicknesses of $30.3-80.0 \mathrm{~nm}$ are sharper and shallower than the experimental curves. This is due to the simple assumption that the reflectivity in the angle range $(\theta \pm \Delta \theta)$ of SPR becomes zero if a single reflection is employed without a range of angles, which is in spite of an angle distribution in the SPR spectrum in a multi-reflection and the range of incident angles in the multi-mode optical fiber. ${ }^{47,49,50}$ The intensity distribution of the laser used in the theoretical calculations may be narrower than the actual distribution. ${ }^{47,49,50}$ The theoretical response curves have slight asymmetrical shapes caused by the responses of the thinner parts of the films at higher refractivities. ${ }^{49}$ The response of the theoretical curve becomes higher as the film thickness increases in contrast to the experimental curve. This is probably due to the neglect of the imaginary part of the dielectric constant of the $\mathrm{Ag}$ films. Differences of the dielectric constant between very thin films and thicker films used in the present theoretical calculations may be present. These theoretical curves show that our theoretical analysis is applicable to the responses of the sensors with film thicknesses of $30.3-80.0 \mathrm{~nm}$.

The refractivities at the minima in the theoretical response curves are shown in Table 3 . The uncertainties were estimated to be less than $0.001 \mathrm{RI}$ units and they were mainly caused by that $\left( \pm 0.1^{\circ}\right)$ of $\Delta \theta\left(0.5^{\circ}\right)$ used. The theoretical curves of the sensors with a thickness of 30.3 and $40.4 \mathrm{~nm}$ have minima at higher refractivities ( $>0.01 \mathrm{RI}$ units) than the corresponding experimental curves. The difference in the refractivities at the minima of the theoretical and experimental curves becomes smaller (about $0.005 \mathrm{RI}$ units) as the film thickness increases. It is considered that this small difference between the theoretical calculations and the experimental results is mainly caused by the neglect of the very thin $(0.3 \mathrm{~nm})$ native oxide layer on the $\mathrm{Ag}$ films due to a lack of information on the chemical state and an appropriate value of the dielectric constant of the surface oxide. The response curves of the sensors were calculated again with the consideration of oxide layers with various thicknesses and dielectric constants. ${ }^{38,40}$ The refractivities at the minima in the calculated response curves of these sensors with oxide layers shift to lower refractivities. The theoretical analysis shows that the surface characterization of the deposited $\mathrm{Ag}$ films and our model for the response of the Ag-deposited optical fiber are appropriate to evaluate the sensor properties.

\section{Conclusions}

A thorough study of Ag-deposited SPR optical fiber sensors has been performed. The response of the Ag-deposited SPR optical fiber sensor depends on the thickness of the $\mathrm{Ag}$ film. We conclude that the properties of the Ag-deposited optical fiber sensor can be controlled by the Ag film thickness. Though the SPR optical fiber sensor with Ag shows a lower sensitivity than the Au-deposited SPR optical fiber sensor in a lower refractivity range (1.327 - 1.361 RI units), the Ag-deposited SPR optical fiber sensor has a similar response range. The detection limit is almost equal to that of an Abbe refractometer. The Ag-deposited SPR optical fiber sensor also has stable sensor properties for periods of over 4 months. The surface characterization of the Ag films by XPS showed the presence of the very thin $(0.3 \mathrm{~nm})$ native oxide layers. The response curves of the sensors agreed reasonably with those calculated from SPR theoretical equations with the consideration of the thickness distribution in the deposited Ag films having no oxide layers on the surfaces.

\section{Acknowledgements}

We thank Mr. A. Nagaura and Mr. T. Ohata for their cooperation. The present study was partially supported by a Grant-in-Aid for Scientific Research (No. 16550080) from the Ministry of Education, Culture, Sports, Science, and Technology, grants from the Kagoshima Science Scholarship Foundation (2005), and the Iketani Science and Technology Foundation (No. 0171025-A). 


\section{References}

1. J. Homola, S. S. Yee, and G. Gauglitz, Sens. Actuators, B, 1999, $54,3$.

2. J. Homola, Anal. Bioanal. Chem., 2003, 377, 528.

3. X. Liu, D. Song, Q. Zhang, Y. Tian, L. Ding, and H. Zhang, Trends Anal. Chem., 2005, 24, 887.

4. W. H. Weber and S. L. McCarthy, Phys. Rev. B, 1975, 12, 5643.

5. M. A. Ordal, L. L. Long, R. J. Bell, S. E. Bell, R. R. Bell, R. W. Alexander, and C. A. Ward, Appl. Opt., 1983, 22, 1099.

6. R. D. Olney and R. J. Romagnoli, Appl. Opt., 1987, 26, 2279.

7. J. W. Sadowski, J. Lekkala, and I. Vikholm, Biosens. Bioelectron., 1991, 6, 439.

8. R. C. Jorgenson and S. S. Yee, Sens. Actuators, B, 1993, 12, 213.

9. R. C. Jorgenson and S. S. Yee, Sens. Actuators, A, 1994, 43, 44.

10. L. A. Obando and K. S. Booksh, Anal. Chem., 1999, 71, 5116.

11. L. A. Obando, D. J. Gentleman, J. R. Holloway, and K. S. Booksh, Sens. Actuators, B, 2004, 100, 439.

12. B. Grunwald and G. Holst, Sens. Actuators, A, 2004, 113, 174.

13. M. Iga, A. Seki, and K. Watanabe, Sens. Actuators, B, 2004, 101,368

14. M. Iga, A. Seki, and K. Watanabe, Sens. Actuators, B, 2005, 106, 363.

15. H. Suzuki, M. Sugimoto, Y. Matsui, and J. Kondoh, Meas. Sci. Technol., 2006, 17, 1547.

16. K. Balaa, M. Kanso, S. Cuenot, T. Minea, and G. Louarn, Sens. Actuators, B, 2007, 126, 198.

17. H. Suzuki, M. Sugimoto, Y. Matsui, and J. Kondoh, Sens. Actuators, B, 2008, 132, 26.

18. C. Ronot-Trioli, A. Trouillet, C. Veillas, A. El-Shaikh, and H. Gagnaire, Anal. Chim. Acta, 1996, 319, 121.

19. A. Trouillet, C. Ronot-Trioli, C. Veillas, and H. Gagnaire, Pure Appl. Opt., 1996, 5, 227.

20. C. Ronot-Trioli, A. Trouillet, C. Veillas, and H. Gagnaire, Sens. Actuators, A, 1996, 54, 589.

21. A. Abdelghani, J. M. Chovelon, J. M. Krafft, N. Jaffrezic-Renault, A. Trouillet, C. Veillas, C. Ronot-Trioli, and H. Gagnaire, Thin Solid Films, 1996, 284/285, 157.

22. A. Abdelghani, C. Veillas, J. M. Chovelon, N. Jaffrezic-Renault, and H. Gagnaire, Synth. Met., 1997, 90, 193.

23. A. Abdelghani, J. M. Chovelon, N. Jaffrezic-Renault, C. Ronot-Trioli, C. Veillas, and H. Gagnaire, Sens. Actuators, $B, \mathbf{1 9 9 7}, 38 / 39,407$.

24. A. Trouillet, C. Veillas, J. P. Goure, and H. Gagnaire, SPIE, 1998, 3483, 109 .

25. W. B. Lin, N. Jaffrezic-Renault, A. Gagnaire, and H Gagnaire, Sens. Actuators, 2000, 84, 198.

26. W. B. Lin, J. M. Chovelon, and N. Jaffrezic-Renault, Appl. Opt., 2000, 39, 3261.
27. W. B. Lin, M. Lacroix, J. M. Chovelon, N. Jaffrezic-Renault, and H. Gagnaire, Sens. Actuators, B, 2001, 75, 203.

28. A. Abdelghani and N. Jaffrezic-Renault, Sens. Actuators, B, 2001, 74, 117.

29. R. Alonso, F. Villuendas, J. Tornos, and J. Pelayo, Sens. Actuators, A, 1993, 37/38, 187.

30. J. Homola, Sens. Actuators, B, 1995, 29, 401.

31. J. Homola and R. Slavík, Electron. Lett., 1996, 32, 480

32. R. Slavík, J. Homola, and J. Čtyroký, SPIE, 1997, 3105, 325.

33. R. Slavík, J. Homola, and J. Čtyroký, Sens. Actuators, B, 1998, $51,311$.

34. R. Slavík, J. Homola, and J. Čtyroký, Sens. Actuators, B, 1999, 54,74

35. R. Slavík, J. Homola, J. Čtyroký, and E. Brynda, Sens Actuators, B, 2001, 74, 106.

36. R. Slavík, J. Homola, and E. Brynda, Biosens. Bioelectron., 2002, 17, 591.

37. M. Piliarik, J. Homola, Z. Maníková, and J. Čtyroký, Sens. Actuators, B, 2003, 90, 236.

38. Y. Xu, N. B. Jones, J. C. Fothergill, and C. D. Hanning, J. Mod. Opt., 2000, 47, 1099.

39. A. K. Sharma and B. D. Gupta, Sens. Actuators, B, 2004 $100,423$.

40. Y. Xu, A. Cottenden, and N. B. Jones, Opt. Quantum Electron., 2005, 37, 1129

41. A. K. Sharma and B. D. Gupta, J. Appl. Phys., 2007, 101, 93111.

42. A. K. Sharma and G. J. Mohr, J. Phys. D, 2008, 41, 55106

43. M. Mitsushio and S. Kamata, Bunseki Kagaku, 1999, 48, 757.

44. M. Mitsushio, T. Yoshidome, and S. Kamata, Bunseki Kagaku, 2000, 49, 307.

45. M. Mitsushio, S. Higashi, and M. Higo, Anal. Sci., 2001, 17(Supple.), i1721.

46. M. Mitsushio, S. Higashi, and M. Higo, Bunseki Kagaku, 2003, 52, 433 .

47. M. Mitsushio, S. Higashi, and M. Higo, Anal. Sci., 2003, 19, 1421.

48. M. Mitsushio, S. Higashi, and M. Higo, Sens. Actuators, A, 2004, 111, 252 .

49. M. Mitsushio and M. Higo, Anal. Sci., 2004, 20, 689.

50. M. Mitsushio, K. Miyashita, and M. Higo, Sens. Actuators, A, 2006, 125, 296

51. M. Higo, K. Fujita, Y. Tanaka, M. Mitsushio, and T. Yoshidome, Appl. Surf. Sci., 2006, 252, 5083.

52. M. Higo, K. Fujita, M. Mitsushio, T. Yoshidome, and T. Kakoi, Thin Solid Films, 2007, 516, 17

53. M. Higo, T. Miake, M. Mitsushio, T. Yoshidome, and Y. Ozono, Appl. Surf. Sci., 2008, 254, 3829.

54. M. Higo, T. Miake, M. Mitsushio, T. Yoshidome, and Y. Ozono, Anal. Sci., 2008, 24, 313.

55. D. Briggs and M. P. Seah, "Practical Surface Analysis by Auger and X-ray Photoelectron Spectroscopy", 1983, John Wiley \& Sons, Sussex.

56. M. P. Seah and W. A. Dench, Surf. Interface Anal., 1979, 1, 2. 